\title{
A multicriteria approach for evaluating high temperature hydrogen production processes
}

\section{Ouassim Galzim and Christine Mansilla*}

CEA, DEN, I-tésé,

F-91191 Gif-sur-Yvette, France

Fax: +33-1-69-08-35-66

E-mail: ouassim.galzim@cea.fr

E-mail: christine.mansilla@cea.fr

*Corresponding author

\section{Alberto Giaconia}

ENEA - Casaccia Research Centre,

Via Anguillarese 301 Rome, Italy

E-mail: alberto.giaconia@casaccia.enea.it

\section{Sabine Poitou}

CEA, DEN, DTN,

F-13108 Saint-Paul-lez-Durance, France

E-mail: sabine.poitou@cea.fr

\section{Jim Hinkley}

CSIRO,

P.O. Box 330, Newcastle NSW 2300, Australia

E-mail: jim.hinkley@csiro.au

\section{Sune Dalgaard Ebbesen}

Risoe DTU,

Frederiksborgvej 399, P.O. Box 49,

DK-4000 Roskilde, Denmark

E-mail: sune.ebbesen@risoe.dk

\section{Michael Gasik}

Helsinki University of Technology, P.O. Box 11000, FI-00076 Aalto, Finland

E-mail:mgasik@cc.hut.fi 


\section{Thierry Gilardi}

CEA, DEN, DTN,

F-13108 Saint-Paul-lez-Durance, France

E-mail: thierry.gilardi@cea.fr

\section{François Le Naour}

CEA, DRT, LITEN, DTBH,

F-38054 Grenoble, France

E-mail: francois.le-naour@cea.fr

\section{Daniela Graf, Martin Roeb and Christian Sattler}

DLR,

Linder Hoehe, 51147 Koeln, Germany

E-mail: daniela.graf@dlr.de

E-mail: martin.roeb@dlr.de

E-mail: christian.sattler@dlr.de

\section{Raffaele Liberatore and Pietro Tarquini}

ENEA - Casaccia Research Centre,

Via Anguillarese 301 Rome, Italy

E-mail: raffaele.liberatore@casaccia.enea.it

E-mail: pietro.tarquini@casaccia.enea.it

\section{Rafael Moliner and Isabel Suelves}

CSIC,

Miguel Luesma Castan 4, 50015 Zaragoza, Spain

E-mail: rmoliner@icb.csic.es

E-mail: isuelves@icb.csic.es

\section{Daniel Gstoehl}

PSI,

5232 Villigen PSI, Switzerland

E-mail: daniel.gstoehl@psi.ch

\section{Ulrich Vogt}

EMPA,

Überlandstrasse 129, CH-8600 Dübendorf, Switzerland

E-mail: ulrich.vogt@empa.ch 


\section{Ray Allen}

University of Sheffield,

Western Bank Sheffield S10 2TN, UK

E-mail: r.w.k.allen@sheffield.ac.uk

\section{Greg J. Kolb}

SNL,

New Mexico, P.O. Box 5800,

Albuquerque, NM 87185, USA

E-mail: gjkolb@sandia.gov

Abstract: Hydrogen demand has already significantly increased due to the industry needs. Mature technologies based on fossil fuels are not satisfactory due to greenhouse gas concerns. In response, a range of advanced processes are being developed throughout the world.

Within the 'International Energy Agency - Hydrogen Implementing Agreement - Task 25', a multicriteria methodology was developed for the evaluation of high temperature hydrogen production processes. The aim is to guide R\&D strategy by highlighting to which extent the processes may appear promising. The method that was developed is based on the elimination and choice translating the reality (ELECTRE). This study has conducted a first pass application to hydrogen production and highlights the importance of significant weightings and discriminating criteria.

Decision makers can apply this method to extract their own subset of processes from the alternatives, according to their system of values defined through the selection of criteria and the associated weights.

Keywords: high temperature; multicriteria; decision making; decision aiding; elimination and choice translating the reality; ELECTRE; hydrogen production.

Reference to this paper should be made as follows: Galzim, O., Mansilla, C., Giaconia, A., Poitou, S., Hinkley, J., Ebbesen, S.D., Gasik, M., Gilardi, T., Le Naour, F., Graf, D., Roeb, M., Sattler, C., Liberatore, R., Tarquini, P., Moliner, R., Suelves, I., Gstoehl, D., Vogt, U., Allen, R. and Kolb, G.J. (2011) 'A multicriteria approach for evaluating high temperature hydrogen production processes', Int. J. Multicriteria Decision Making, Vol. 1, No. 2, pp.177-204.

Biographical notes: Ouassim Galzim is an Industrial Engineer and holds a Master's degree in Industrial Engineering. He carried out his final training period at the CEA, in the Institute for Techno-Economics of Energy Systems (I-tésé) by focusing on multicriteria decision making for high temperature hydrogen production applications.

Christine Mansilla received his Master's degree in Energy Science and $\mathrm{PhD}$ in Industrial Engineering at the Ecole Centrale de Paris in 2006. Since then, she has been working as a Research Engineer at the CEA, in the Institute for Techno-Economics of Energy Systems (I-tésé), especially in techno-economics for the evaluation of the production cost of advanced hydrogen processes.

Alberto Giaconia is a $\mathrm{PhD}$ Chemical Engineer and graduated at the University of Palermo in 2000. He obtained his $\mathrm{PhD}$ with a thesis on 'Synthesis of polymers in supercritical carbon dioxide'. Since 2004, he is a Researcher at the ENEA (the Italian Agency for New Technologies, Energy and Sustainable 
Economic Development) in the 'Solar Thermodynamic Group'. His research is focused on thermochemical hydrogen production powered by high temperature solar heat. $\mathrm{He}$ is currently working on the sulphur-iodine cycle, and solar-powered methane reforming. He published several papers in international journals and five patent applications. He also cooperates in national and international programmes on high temperature hydrogen production.

Sabine Poitou is a Research Engineer at the Commissariat à l'Energie Atomique (CEA), Cadarache Centre. She studied Chemical Engineering at the Ecole Nationale Supérieure des Industries Chimiques (ENSIC) in the National Polytechnic Institute of Lorraine (1991-1994). Working at CEA since 1998, she was involved on nuclear waste treatment and conditioning studies until 2007. Since 2008, her activity concentrates on industrial development of hydrogen production with nuclear reactor coupled processes.

Jim Hinkley is a Research Team Leader at the CSIRO, Australia's national research organisation. $\mathrm{He}$ is a Chemical Engineer with a broad range of industrial and research experience, from mining and mineral processing to renewable energy. He has worked for large industrial companies in both research and operations roles, and received his $\mathrm{PhD}$ in 2005 from the University of Newcastle for his investigations into the contribution of emissions from coal fired power stations to atmospheric particulates. Since 2004, he has worked with CSIRO at the National Solar Energy Centre in Newcastle, where he has been involved with many aspects of concentrating solar technologies. He is also active in a number of international projects and collaborations for thermochemical hydrogen production.

Sune Dalgaard Ebbesen is working as a Scientist at the Fuel Cells and Solid State Chemistry Division, Risø National Laboratory for Sustainable Energy, Technical University of Denmark. His research is focused on alkaline cells for high temperature electrolysis of $\mathrm{H}_{2} \mathrm{O}$ and on solid oxide cells for high temperature electrolysis of $\mathrm{H}_{2} \mathrm{O}$ and $\mathrm{CO}_{2}$ and co-electrolysis of $\mathrm{H}_{2} \mathrm{O}$ and $\mathrm{CO}_{2}$. He studied Chemical Engineering at the Aalborg University, Denmark, performed his $\mathrm{PhD}$ research in Heterogeneous Catalysis at the University of Twente, the Netherlands and received his Doctor's degree in 2007

Michael Gasik is a Professor, Dr. Sci. (2000), Dr. Techn. (1995), PhD (1987) and Dipl. Eng. (1983). He is the Head of the group of materials processing of the Department of Materials Science and Engineering, Aalto University Foundation, Espoo, Finland since 1998. Previously, he was a Sensor Research Scientist and Visiting Fellow at the University of Manchester, UK; Tohoku University, Sendai, Japan. $\mathrm{He}$ is an alternating member representative of Finland in IEA Hydrogen Implementation Agreement Executive Committee since 2004 . He is the author of more than 200 papers, proceedings and patents in different fields.

Thierry Gilardi received his $\mathrm{PhD}$ on Oxidation and Reduction Kinetics applied to uranium oxides for nuclear fuel manufacturing, after a Chemical Engineering degree (ENSIC Nancy, France). In 1993, he started to work in CEA as a Process Conduction Manager for UNGG spent fuel chemical stabilisation and reconditioning. Then in 1998, he joined a laboratory in charge of nuclear waste behaviour studies and he was responsible for irradiation effect studies on organic matrix. Since 2005, he was involved in process design and economical assessment in the frame of different projects dealing with hydrogen production using innovative high temperature processes, and in modelling studies of mass transfer phenomenon in various systems. 
François Le Naour is a $\mathrm{PhD}$ Material Engineer and graduated at the Electrochemical and Electrometallurgy Engineers School in 1984. He first worked on material embrittlement on nuclear components. In 1999, he joined the Department of New Technologies for Energy to facilitate the programme 'Production of hydrogen of CEA'. He coordinated, from 2005 to 2007, the European project INNOHYP CA to establish a state of the art on the international high-temperature processes for hydrogen production and propose to the European commission a roadmap for $\mathrm{R} \& \mathrm{D}$ on these processes. He has been the Deputy Head of Department 'Biomass and hydrogen' in charge of strategy and programmes since the beginning of 2010.

Daniela Graf has studied Energy Engineering Management in the Leipzig and received her Diploma in 2005. In the same year, she started working at the German Aerospace Centre in the field of solar research. Within several European projects, she was concerned with dimensioning and economic feasibility studies of solar power plants for hydrogen mass production as well as of solar water treatment. Furthermore, she was involved in experimental campaigns of hydrogen production by solar energy and solar detoxification projects.

Martin Roeb has a background in Chemistry, Physical Chemistry and Solar Engineering. He has many years of extensive research and engineering experience in solar high temperature applications. He has been working as the Package Leader and DLR responsible in several EU projects (FP5 and FP6) and Project Coordinator of domestic research projects in that area. He has been involved in international cooperation in the context of IPHE and SolarPACES.

Christian Sattler studied Chemistry at the University of Bonn. He received his $\mathrm{PhD}$ in 1997. He joined the German Aerospace Centre DLR in 1997 and became the Project Manager in 1999. Since 2003, he is the Research Area Manager for solar materials conversion working in the field of solar fuels, solar water treatment, solar desalination and solar thermo- and photochemistry. Since 2008, he is a member of the board of N.ERGHY the research association within the European Joint Technology Initiative for hydrogen and fuel cells, since 2010, its vice-president. He published more than 200 papers and received a number of awards among them the European Descartes Research Prize 2006.

Raffaele Liberatore is a chemical engineer graduated at the University of Rome 'La Sapienza' with a thesis on 'Biological sewage treatment plants: use of fuzzy logic to handle the uncertainties on the input data and kinetic parameters'. Since 2003, after an experience in the aerospatial industry, he is researcher at the ENEA, working for the 'Solar Thermodynamic Project', with research on thermochemical hydrogen production powered by high temperature solar heat. His activity is focused on the development of the sulfuriodine cycle, and solar-powered ethanol reforming. He published papers in international journals and two patent applications. He also cooperates in National and International programmes on High Temperature Hydrogen Production.

Pietro Tarquini obtained his degree in Chemical Engineering. He worked on promotion of renewable energy use in EU programme (Altener) as contact point for Italy in solar thermal diffusion in industrial and building sectors. Since 2000, he has carried out R\&D activities on thermochemical cycles for hydrogen production as the Head of the heat transfer fluid project of ENEA's solar thermodynamic division. 
Rafael Moliner is a Professor in Research of CSIC. He is the Head of the Fuel Conversion Group at the ICB-CSIC and the Coordinator of the Chemical Science and Technology Area of CSIC. His research topics are production of hydrogen by catalytic decarbonisation of hydrocarbons and materials for energy and environment. He has conducted 16 research projects funded by the European Commission, the Spanish Government and the local government. $\mathrm{He}$ has published 130 papers in international refereed journals covered by the SCI and more than 30 contributions to collective books. He is a co-owner of four patents and has supervised ten $\mathrm{PhD}$.

Isabel Suelves received her $\mathrm{PhD}$ in Chemistry in the Zaragoza University (Spain) in 1998 and spent two years at the Imperial College as a Post-doctoral Researcher. Since 2001, she is working as a Scientific Researcher at the Instituto de Carboquimica (CSIC) in Spain. Her main research lines are production of hydrogen and carbon nanofibers by catalytic decomposition of hydrocarbons and their applications. She has participated in 25 research projects funded by the European Commission, the Spanish and local governments and she has published 72 papers in SCI journals, two book chapters and 39 contributions to collective books. She has a patent application and supervised several doctoral thesis and projects. She also participates as a Teacher in several doctoral and master courses.

Daniel Gstoehl is a Senior Scientist at the Solar Technology Laboratory at the Paul Scherrer Institut (PSI) in Switzerland. He is a Mechanical Engineer. He earned his $\mathrm{PhD}$ in Heat Transfer in 2004 at the Swiss Federal Institute of Technology in Lausanne (EPFL). He first worked as a Project Leader in the industry in the field of spray drying. In 2006, he joined the PSI. He has mainly been working on the thermochemical water splitting $\mathrm{ZnO} / \mathrm{Zn}$ cycle. $\mathrm{He}$ developed a quench unit for the separation of gaseous $\mathrm{Zn}$ and $\mathrm{O}_{2}$, leaded several experimental campaigns improving PSI's reactor technology for the thermal dissociation of $\mathrm{ZnO}$. He also has been active in the field of high temperature electrolysis.

Ulrich Vogt is a Senior Scientist at the EMPA, 'Hydrogen and Energy'. He received his $\mathrm{PhD}$ at the Albert-Ludwig-University, Freiburg, D, by investigating the synthesis of Si3N4 fibres by a gas-phase process. Some topics of his research work have been ceramic processing in general. Since he joined the 'Hydrogen and Energy' Group, he is working on topics among which hydrogen production via 'high temperature steam electrolysis', 'new membrane materials for low temperature water electrolyser'. He authored over 50 publications and presented several invited lectures at international conferences. $\mathrm{He}$ is a Lecturer at the University of Freiburg, D, with the topic materials for energy research.

Ray Allen is a Senior UK Chemical Engineering Academic, a fellow of the Royal Academy of Engineers and the President of the Engineering Professors Council of the UK. He has been the Principal or Co-Investigator in over $£ 4.2 \mathrm{~m}$ worth of projects since 2002 and author of 40 refereed publications since 2001 . $\mathrm{He}$ is the founding Chairman of the HIx Forum, an organisation that he has recently set-up to encourage international collaboration and information exchange within the international community working on the sulphur iodine thermochemical cycle.

Greg J. Kolb has worked as a Systems Engineer at the Sandia National Laboratories since 1978. Most of this time was devoted to the R\&D of large concentrating solar power plants, including projects that significantly reduced operating costs at the 150 MW Kramer Junction solar 
trough plant, as well as the construction and operation of the $10 \mathrm{MW}$ solar two power tower. Most recently he is working with US industry to successfully deploy initial commercial projects and is exploring concepts for next-generation high-temperature power towers appropriate for hydrogen production.

\section{Introduction}

It is now clear that the demand for hydrogen has undergone strong growth with the increasing needs of industry - especially for fertiliser production and in petrochemical refining, while the hydrogen consumption per barrel of oil has doubled over the last 30 years. This growth is likely to continue, and may be augmented by an increased market demand for hydrogen energy. Moreover, synthetic fuels that could replace conventional oil in the medium-term require large amounts of hydrogen. Mature technologies based on fossil fuels are not satisfactory due to limited resources and the greenhouse gas emissions that are generated. Only alkaline electrolysis can presently produce hydrogen without emitting greenhouse gases, provided of course the consumed electricity is also produced without causing emissions. So-called advanced processes, or high temperature processes, such as high-temperature electrolysis or thermochemical cycles, can be powered by carbon-free heat sources like nuclear and concentrated solar energy and may be more efficient than low temperature processes, thereby reducing power consumption and possibly hydrogen production cost as a consequence. The possibility of better efficiency is the initial driver of interest in these processes.

These processes are very different (in terms of process characteristics, maturity, etc.), which makes objective comparison difficult. Previous studies used the efficiency of the process as the principal basis for comparison (Lewis et al., 2009). The efficiency is of course an important parameter since it is related to the process sustainability and cost to some extent. Consequently some studies focus on efficiency optimisation through process integration (Andress et al., 2009). However, considering the efficiency alone is limiting. Indeed the energy source may be renewable, so that increasing the energy consumption may not reduce sustainability. Conversely, increasing the efficiency may increase production costs out of proportion to their benefit.

It is likewise difficult to compare processes on the basis of production cost. Recent studies have been carried out, either in the context of a solar heat source (Graf et al., 2008) or coupling to a nuclear reactor (McLaughlin et al., 2006; Yang et al., 2008). The results are strongly dependent on the economic model which is implemented and assumptions about the maturity of processes and especially the underlying cost data, which makes comparison difficult.

Due to the increasing demand for hydrogen, R\&D is assessing promising high temperature processes and needs to be guided for effectiveness. As a result, within the International Energy Agency - Hydrogen Implementing Agreement, a special task was devoted to high temperature hydrogen processes (Task 25) uniting the solar and nuclear hydrogen production communities. Over 20 experts from twelve different countries participate in this collaboration. Their broad fields of expertise encompass 
chemical engineering, industrial engineering, materials science, chemistry and electrochemistry.

One of the missions assigned to this task is to develop a multicriteria assessment method, which assesses the weaknesses and strengths of the various processes in specific energy scenarios (e.g., high fossil fuel prices in the medium term, natural gas shortage), in order to facilitate the development of high temperature processes for massive production of hydrogen with minimal greenhouse gas emissions. The general goal of the hydrogen production process assessment is thus to identify a subset of promising processes, defined according to their evaluation against a set of criteria.

In such a framework the process comparison cannot be restricted to technical performance but needs to be widened to include economic and environmental issues. The results of this study will help define $R \& D$ objectives to make a process competitive for future massive hydrogen production. This paper presents the methodology that was developed, which is based on multicriteria decision making (MCDM) methods, with the aim of taking into account:

- the multi-technology aspect: the studied processes employ very different technologies

- the different states of development of the processes: some of the studied processes are firmly in R\&D, while others are at the pilot plant stage

- the data uncertainty: due to the early stage of development of some processes

- non-comparable criteria: because very different criteria such as production costs or $\mathrm{CO}_{2}$ emissions should be considered.

The first part of the paper is dedicated to the selection of the method, and its implementation to the evaluation of hydrogen production processes. The second part presents the initial results, verifying the consistency of the method and the need for further studies.

\section{Selection of a method and implementation to assess hydrogen production processes}

\subsection{Selection of the method}

Different studies have already been carried out to assess hydrogen production processes. The first ones mentioned above focus on the efficiency of the process: the work carried out by Lewis et al. (2009) deals with three levels of efficiency - progressively more detailed - before conducting a down-screening process including other technical criteria: the chemical viability and engineering feasibility to meet the US Department Of Energy (DOE) timeline ("to operate a nuclear hydrogen production plant at a cost competitive with other alternative transportation fuels by 2019", Lewis and Masin, 2009). Numerous thermochemical cycles have been examined identifying 'show-stoppers' for some of them. This method provides a go/no go decision for the processes on technical grounds. As it was mentioned earlier, other types of criteria should be included in a robust 
approach with longer term considerations; therefore a process should not be definitively screened out because of a poor engineering feasibility today.

Hydrogen production processes have already been compared through the establishment of figures of merit (Ewan and Allen, 2005) and hydrogen chains through the definition of sustainability index (Afgan et al., 2007). The method detailed by Ewan and Allen (2005) normalises environmental and economic criteria before defining the process figure of merit as the product of the normalised criteria. Such a method considers each criterion as important as the next one. Moreover, through the product calculation, it is possible to offset bad performances: a process with a high performance in one criterion and a bad one in another will not be distinguished from a process with average performances on both criteria. The definition of a sustainability index, as it is done by Afgan et al. (2007), has the same drawback: a weighted sum is calculated from four economic and one environmental criteria.

The methods that are developed by Ewan and Allen (2005) and Afgan et al. (2007) belong to the compensatory MCDM model family: all criterion values are aggregated in a single evaluation value to rank all the alternatives. Compensatory MCDM models have been mainly based on the multi-attribute utility theory (MAUT, cf., Saaty, 1980) where a single overall criterion is postulated and optimised. Contrary to such an approach, noncompensatory MCDM models are mainly based on pair wise comparisons of alternatives, which are made with respect to individual criteria. An example of the latter approach is the elimination and choice translating the reality (ELECTRE) method, first developed by Roy (1985) and detailed by Figueira et al. (2005). The weights in ELECTRE are coefficients of importance and not criterion substitution rates; and a very 'bad' value on one criterion cannot be offset by 'good' values on other criteria through the use of vetoes. According to this method, processes may then not be directly compared when a given process cannot be declared either superior or inferior to the next one; this is termed 'non-comparable'.

In this case, the objective of the study is not to classify the processes from the best to the worst, but to compare each process to the others and highlight strengths and weaknesses in order to obtain a subset of interesting processes (in the identified subset the processes are equally regarded). For instance a process could be environment-friendly but quite complex and expensive. The aim is to find out whether these characteristics allow it to appear among the most promising processes, when compared to the other available processes.

Method parameters will allow widening or tightening this subset as is explained later. The ELECTRE 1 method seems well-suited to reach this objective, since it is a non-compensatory method that was designed to solve such decision-aiding problems (as opposed to other ELECTRE methods aiming at ranking actions). Moreover, the uncertainties can be important due to the nature of the retained criteria (economic ones for instance). This is acknowledged by using ELECTRE $1 \mathrm{~S}$ which employs fuzzy logic to permit the use of pseudo-criteria' ( $\mathrm{S}$ means 'Seuil', i.e., threshold in French). The ELECTRE 1S software was provided by the LAMSADE to perform all needed calculations. The LAMSADE laboratory was established in 1974 as a joint laboratory of the Université Paris-Dauphine and the CNRS (LAMSADE, 2009). Its central research activity lies at the interface of two fundamental scientific areas: computer science and decision making (and, more generally, operations research). 


\subsection{Description of the method}

The general goal of the hydrogen production process assessment is to identify a subset of promising processes, which is defined according to their evaluation against a set of criteria. Criteria 'agree' or not with the fact that a given process is interesting compared to others. One could also compare it to a voting procedure, in which each criterion has one vote to express its opinion about the statement "action $a$ is at least as good as action $b$ ". This vote is balanced according to the importance assigned to the assessed criterion.

In methodological terms, the kernel (i.e., best subset) is identified through pair wise comparisons of alternatives (also called actions, i.e., the various hydrogen production processes). The outranking of an alternative by another one is established through the concordance ('agreement') or discordance ('disagreement') concepts. Criteria are in accordance or not with the statement "action $a$ is at least as good as action $b$ (i.e., action $a$ outranks action $b$ )". Actions within the kernel are equally regarded: they are the selected actions.

A first step in the decision making process is to identify the decision maker to whom the study is intended (e.g., a politician willing to fund $\mathrm{R} \& \mathrm{D}$, or an industrial company needing to implement a process). In this case, the role is filled by the IEA/HIA - Task 25 group members. Having several participants involved in the process raised several issues, especially regarding how to take into account the stakeholders' different value systems. This is detailed in the next section, with an explanation of the method implementation to this specific study.

A set of potential actions that covers the most important alternatives in the point of view of the decision maker is then defined. For this study, the actions are hydrogen production processes.

A set of criteria is also proposed and discussed before being validated. This set must satisfy all the assumptions of a criterion family: exhaustive, coherent and not redundant. Once the processes and the criteria are identified, the assessment matrix (Table 1) is built. In case of disagreement on the values of the matrix, compromises have to be made to satisfy the majority of the stakeholders. It can be highlighted here that the most difficult was of course to agree on production costs: assumptions are different depending on the countries, as well as the level of detail applied. It was therefore agreed that the defined assessment matrix is a first case study to highlight the potential of the method.

Table 1 Assessment matrix example ( $a_{i}$ : action; $g_{j}$ : criterion)

\begin{tabular}{cccccc}
\hline & $g_{1}$ & $g_{2}$ & $\ldots$ & $g_{j}$ & $\ldots$ \\
\hline$a_{1}$ & $g_{1}\left(a_{1}\right)$ & $\ldots$ & $\ldots$ & $\ldots$ & $\ldots$ \\
$a_{2}$ & $\ldots$ & $\ldots$ & $\ldots$ & $\ldots$ & $\ldots$ \\
$\ldots$ & $\ldots$ & $\ldots$ & $\ldots$ & $\ldots$ & $\ldots$ \\
$a_{\mathrm{k}}$ & $\ldots$ & $\ldots$ & $\ldots$ & $g_{j}\left(a_{k}\right)$ & $\ldots$ \\
$\ldots$ & $\ldots$ & $\ldots$ & $\ldots$ & $\ldots$ & $\ldots$ \\
\hline
\end{tabular}

Once the matrix is filled, the following method parameters are needed:

- The objective function type means whether the criterion should be maximised or minimised (e.g., a production cost should of course be minimised whereas the process efficiency should be maximised). 
- $\quad$ The indifference and preference thresholds help express the scatter of data due to the different points of view of the experts, or the uncertainty of data. For instance, one may consider that $0.05 € / \mathrm{kg}_{\mathrm{H} 2}$ is not significant to distinguish two processes (indifference), whereas $0.3 € / \mathrm{kg}_{\mathrm{H} 2}$ is significant (preference threshold). Each criterion has a structure of preference defined by the indifference threshold and the preference threshold, and is associated with a scale.

- The veto threshold indicates the gap that overrules an outranking for a given criterion. For example, an extremely high level of toxicity could be considered a 'show-stopper' regardless of other process characteristics. Trade-offs between criteria is avoided by the introduction of a veto.

- The weight reflects the relative importance of the criterion among the set. It is usually established through criterion ranking.

Through the definition of these parameters, the decision maker's own system of values is made explicit and organised, e.g., does he favour economics over environmental benefits, or the other way around? Indeed when numerous and conflicting criteria are at stake, common sense may not be enough to globally assess several alternatives. An important contribution of this method is that it provides the framework for discussion and debate, especially since several stakeholders are involved in this study. The co-construction of the model through the interaction of the experts is a part of the 'European' conception of decision aiding, as it is explained by Roy (2010).

The results of such a study may only be considered 'subjective' in the sense that they depend on the decision maker's own value system, a value system that is made clear through the use of the methodology. In this case the input assumptions reflect the wider level of understanding of the IEA Task 25 group members about the various processes being evaluated. Similar approaches are detailed by McDowall and Eames (2007) and Yüzügüllü and Deason (2007). The methodology is a thinking process in which iteration is allowed and encouraged: assumptions may be revised as well as preferences.

Finally a pair wise comparison of alternatives is carried out to identify the best subset of alternatives according to the decision maker's value system. The action $a$ outranks the action $b$ means that the action $a$ is at least as good as the action $b$. The action $a$ outranks the action $b$, only if most of the criteria accept that $a$ is at least as good as $b$, i.e., the global concordance index is higher than a defined threshold (called the concordance threshold), and if there is no criterion that uses its veto against this statement (e.g., if the value of the veto is set to five for a criterion for which $a$ is rated 1 and $b 7$, the relationship ' $a$ outranks $b$ ' is refused whatever the evaluation of the other criteria).

The global concordance index of the relationship ' $a$ outranks $b$ ' is designated by $C(a, b)$ :

$$
C(a, b)=\sum_{j} k_{j} \cdot c_{j}(a, b)
$$

where $k_{j}$ is the weight of the criterion $j$ and where $c_{j}(a, b)$ is the partial concordance index of the relationship ' $a$ outranks $b$ ' according to the criterion $j$, defined by equation (1): 


$$
c_{j}(a, b)=\left\{\begin{array}{l}
1 \text { if } g_{j}(b)-q_{j} \leq g_{j}(a) \\
\frac{p_{j}-\left[g_{j}(b)-g_{j}(a)\right]}{p_{j}-q_{j}} \\
0 \text { if } g_{j}(a) \leq g_{j}(b)-p_{j}
\end{array} \text { if } g_{j}(b)-p_{j} \leq g_{j}(a) \leq g_{j}(b)-q_{j}\right.
$$

$g_{j}\left(a_{i}\right)$ is the assessment of the action $a_{i}$ according to the criterion $j$. The indifference threshold for the criterion $j$ is noted $q_{j}$, and the preference threshold for the criterion $j$ is noted $p_{j}$.

Figure 1 illustrates this preference structure. When $a$ is slightly or strictly preferred to $b$, or even when $a$ is equivalent to $b$, the partial concordance index of the relationship ' $a$ outranks $b$ ' is equal to 1 . Thus even if the two actions are within the indifference threshold, the criterion still contributes to the outranking.

Figure 1 Preference structure of a given criterion ( $g$ is the assessment according to the regarded criterion) (see online version for colours)

$\mathrm{b}$ is strictly $\mathrm{b}$ is slightly
preferred to a preferred to $\mathrm{a}$,

Figure 2 Outranking graph example (see online version for colours)

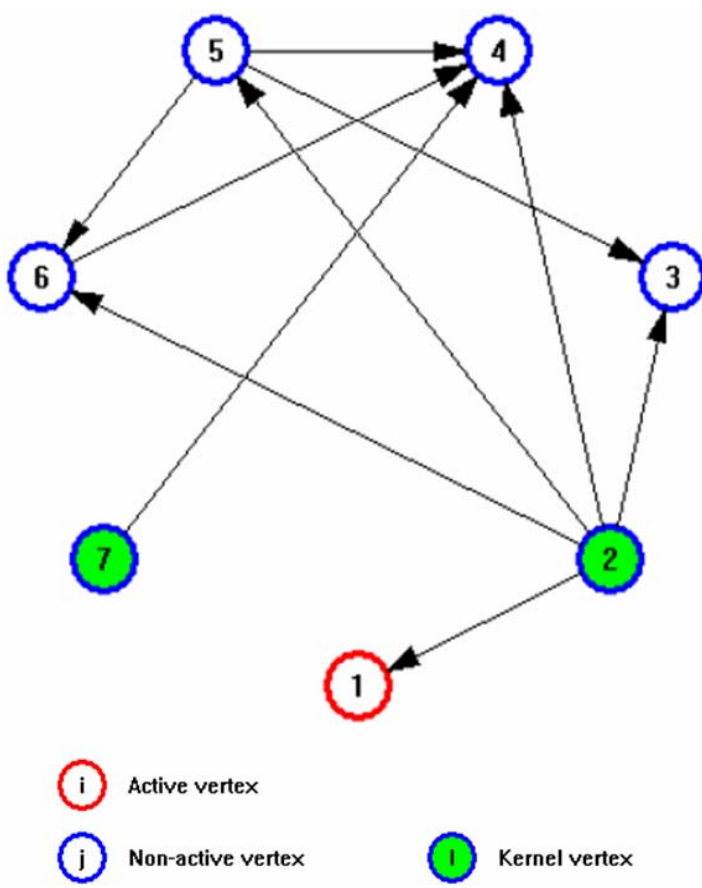

Notes: Outranking relationships are symbolised by arrows. The active vertex is the process which is selected in the software by clicking. The kernel vertexes are the selected processes. 
The outranking graph visualises the outranking relationships for the set of couples $(a, b)$. According to the graph theory, each action is represented with a vertex (Figures 2 to 5). If the action $a$ outranks the action $b$, a pointing arrow is drawn from the vertex $a$ to the vertex $b$. If no outranking relationship exists, then no arrow is drawn between the two vertexes (this happens when the global concordance index is lower than the selected concordance threshold both for the relationships ' $a$ outranks $b$ ' and ' $b$ outranks $a^{\prime}$ ). In the example in Figure 2 for instance, Action 5 outranks Actions 3, 4, 6 and it is outranked by Action 2 .

Figure 3 Short-term scenario - reference case $-s=0.74$ - final outranking graph (see online version for colours)

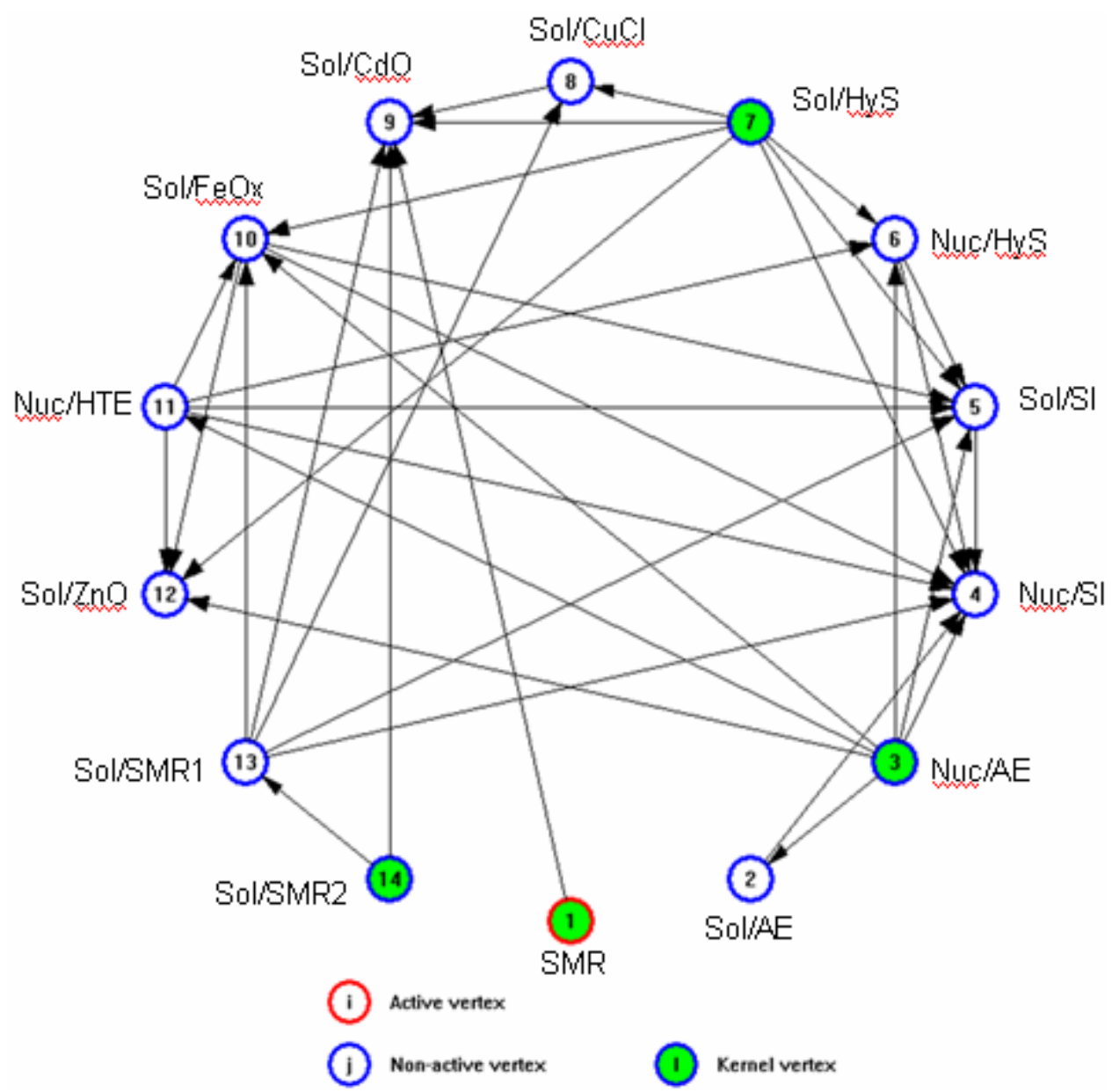

Notes: Outranking relationships are symbolised by arrows and the alternatives' numbers and abbreviations refer to Section 2.3. The active vertex is the process which is clicked on. The kernel vertexes are the selected processes. 
Figure 4 Long-term scenario - reference case $-s=0.74$ - modified outranking graph (see online version for colours)

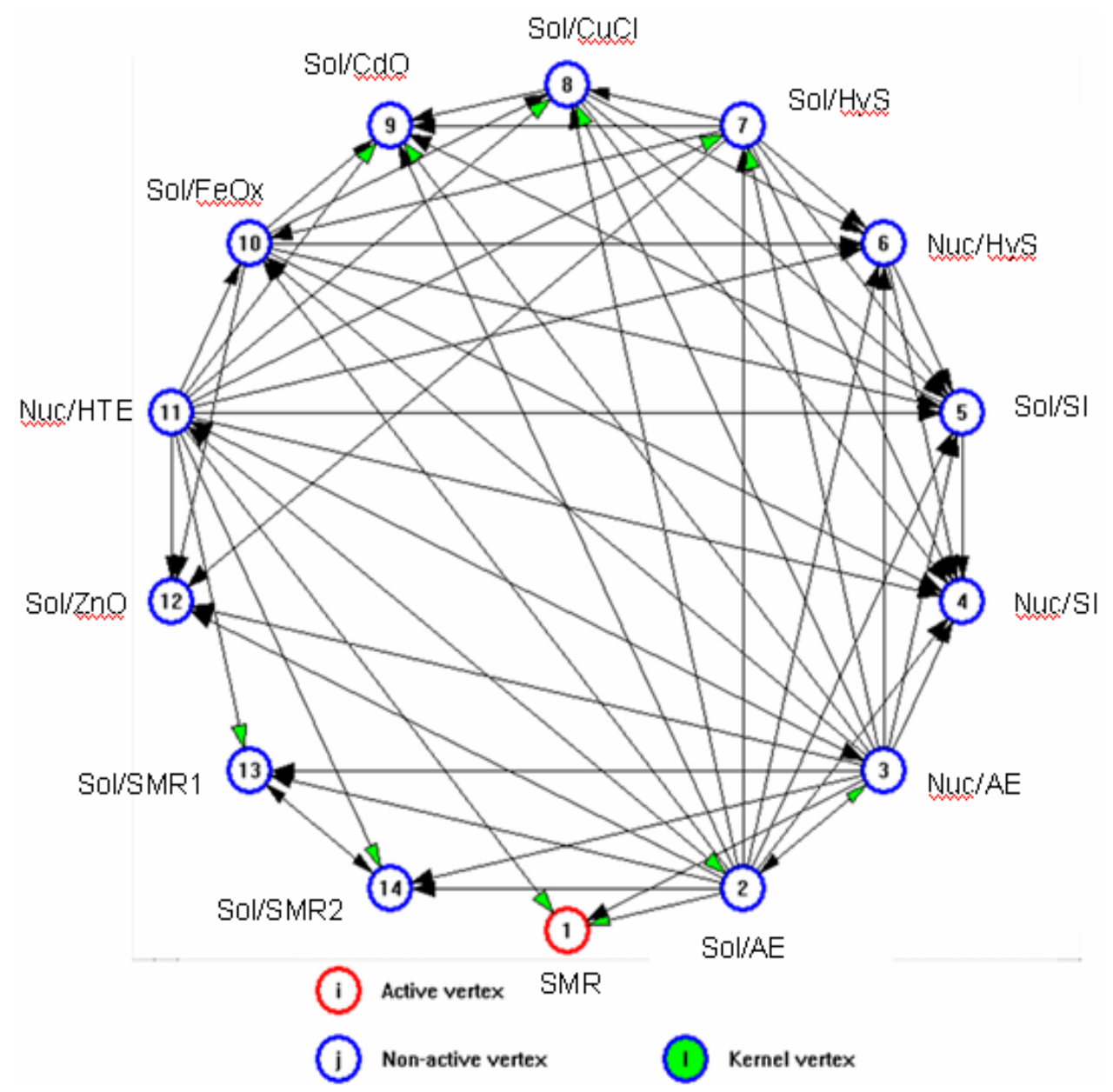

Notes: (Outranking relationships are symbolised by arrows, in green when having been modified by the software. Abbreviations refer to Section 2.3. The active vertex is the process which is clicked on. The kernel vertexes are the selected processes. 
Figure 5 Long-term scenario - reference case $-s=0.74$ - final outranking graph (see online version for colours)

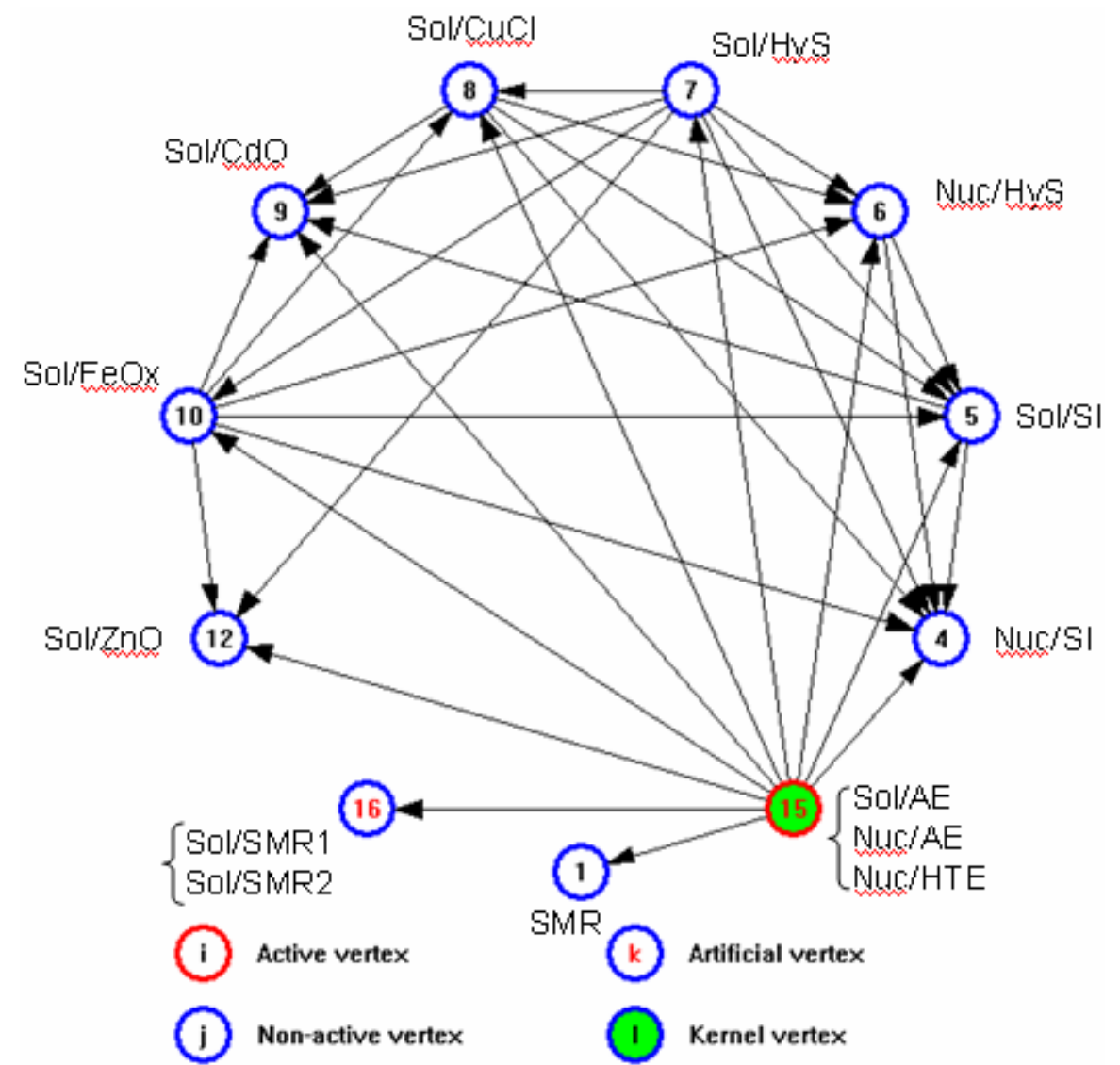

Notes: Outranking relationships are symbolised by arrows. Abbreviations refer to

Section 2.3. The active vertex is the process which is clicked on. The kernel vertexes are the selected processes. Artificial vertexes stand for several processes gathered in one because of their comparable performances as regards the considered criteria.

The kernel (selected subset of processes) is defined by:

- all processes which do not belong to the kernel are outranked by at least one process in the kernel (i.e., a given process is not in the kernel because a 'better' process could be found)

- the processes included in the kernel are not outranked by any process within it (i.e., all the processes of the kernel are equally regarded).

\subsection{Implementation of the method to assess hydrogen production processes - a search for consensus}

The major task of the method implementation to the assessment of high temperature hydrogen processes was the co-construction and population of a common value system 
with the group of experts. Consensus was sought when defining the preference model, as well as when assessing the processes according to this model.

\subsubsection{Selection of the processes}

Fourteen hydrogen production processes were considered. Benchmark processes such as steam methane reforming (the cheapest process today) and alkaline electrolysis have been included in the study. The other processes that have been considered emerged from the expert group as potentially promising processes in the longer-term. Among them are several thermochemical cycles which involve the dissociation of the water molecule using heat rather than electricity. The key feature of these cycles is the use of intermediate materials to reduce the extreme temperature that would be needed for direct thermal decomposition of water into hydrogen and oxygen. High temperature electrolysis was also considered, which has a lower electrical demand than conventional alkaline electrolysis, as hydrogen is produced from steam inside high temperature electrolysis cells.

The processes selected for the study are:

1 Steam methane reforming (SMR): Steam reforming of natural gas is the most common method of hydrogen production; it is a mature process and widely used today (IEA/HIA Task 25, 2010c).

2 Solar alkaline electrolysis (Sol/AE): Alkaline electrolysis is a mature technology based on the electrochemical splitting of water into oxygen and hydrogen using a conductive electrolyte. The electricity required for the electrolysis is generated by solar energy (Graf et al., 2008).

3 Nuclear alkaline electrolysis (Nuc/AE): As above, except that the electricity required is generated by a nuclear plant.

4 Nuclear sulphur iodine cycle (Nuc/SI): The sulphur-iodine thermochemical cycle is a three-step thermochemical cycle. It has been demonstrated at lab scale (IEA/HIA Task 25, 2010d). Thermal energy is provided by an advanced nuclear reactor (Leybros et al., 2010a).

5 Solar sulphur iodine cycle (Sol/SI): Thermal energy is provided by a solar plant in this case (IEA/HIA Task 25, 2010d).

6 Nuclear hybrid sulphur cycle (Nuc/HyS): The hybrid sulphur cycle, also known as the Westinghouse process, is a two-step cycle including a thermochemical step and an electrolysis step (IEA/HIA Task 25, 2010b; Leybros et al., 2010b).

7 Solar hybrid sulphur cycle (Sol/HyS): The source of the primary thermal energy is a central solar receiver instead of advanced nuclear reactors (IEA/HIA Task 25, 2010b).

8 Solar copper chloride cycle ( $\mathrm{Sol} / \mathrm{CuCl}$ ): The solar copper chloride cycle is a threestep process: it includes a hydrolysis reaction, oxy-chloride decomposition and electrolysis (Kolb, 2009).

9 Solar cadmium cycle ( $\mathrm{Sol} / \mathrm{CdO}$ ): The solar cadmium cycle consists of three steps: oxide decomposition, cadmium vapour quenching and hydrogen generation through hydrolysis (Kolb, 2009). 
10 Solar ferrite cycle ( $\mathrm{Sol} / \mathrm{FeO}$ ): The solar ferrite cycle is a two-step thermochemical water splitting cycle: solar thermal reduction and steam oxidation (Kolb, 2009).

11 Nuclear high temperature electrolysis (Nuc/HTE): High temperature electrolysis in solid oxide cells (SOEC) consists of electrolysing steam, instead of liquid, at high temperature, reducing the electricity demand (IEA/HIA Task 25, 2010a).

12 Solar $\mathrm{Zn} / \mathrm{ZnO}$ cycle ( $\mathrm{Sol} / \mathrm{ZnO}$ ): Hydrogen is produced from water using solar energy via a two-step thermochemical cycle. It is based on simple chemistry analogous to the solar cadmium cycle, but requires a very high temperature (IEA/HIA Task 25, 2010e).

13 Solar steam methane reforming 1 (Sol/SMR1): The entire chemical process, comprising reforming reactors, steam generator, and separation units is powered using a molten salt mixture at $550^{\circ} \mathrm{C}$ as the solar heat carrier (Giaconia et al., 2008).

14 Solar steam methane reforming 2 (Sol/SMR2): There are different configurations for the solar steam methane reforming cycle, so two different flow sheets have been studied (Giaconia et al., 2008).

It should be highlighted once more that steam methane reforming is a benchmark process only; the IEA/HIA - Task 25 project is dedicated to carbon-free processes. Solar steam reforming was also included as an option to reduce the environmental footprint of the most common method of hydrogen production today: classical steam methane reforming. For space matters, the processes will not be further detailed hereafter.

\subsubsection{Selection of the criteria}

In order to assess the processes retained for the study, criteria were defined through discussion among the experts. A first set of criteria was defined and proposed for validation. The proposed criteria were defined to ensure a common understanding of all the group members. Further, the experts were asked to give the assumptions or the calculation methods to determine comparable values.

After several exchanges some criteria were added (the process complexity because of its influence on the decision to implement a given process) and others were removed (investment and land use). The investment and land use criteria were not suitable for assessment due to a lack of information for the different processes. However, these factors are not completely ignored, since the production cost takes them into consideration. Finally, the family of criteria was validated.

The selected criteria are:

- Production cost $\left(€_{2009} / \mathrm{kg}\right)$ : including all cost items (investment, energy consumption, etc.).

- Maturity $\left(10\right.$ to $\left.40^{2}\right)$ : indicates the maturity level of the technology used.

- Direct $\mathrm{CO}_{2}$ emissions $\left(\mathrm{kg}_{\mathrm{CO}_{2}} / \mathrm{kg}_{\mathrm{H} 2}\right)$ : only includes the emissions due to the process itself (without 'carbon footprint' of the plant), and does not include emissions due to the electricity consumption. Electricity consumption was excluded because it is related to the energy mix of the site where the process would be implemented and is not a characteristic of the process itself. 
- Efficiency: of the hydrogen production process as an indicator of whether it makes 'good' use of available energy.

- Process resource availability $\left(10\right.$ to $\left.40^{3}\right)$ : the present estimated lifetime of the energy source for the process.

- Maximum process temperature $\left({ }^{\circ} \mathrm{C}\right)$ : design temperature of the highest temperature step of the process (high temperatures imply high investments but are also related to the availability of the energy source. For instance a nuclear driven process operating at $800^{\circ} \mathrm{C}$ would require the development of high temperature nuclear reactors).

- Environmental threat/toxicity $\left(10\right.$ to $\left.40^{4}\right)$ : of the raw materials or products involved in the process, including chemicals internally re-circulated (e.g., sulphuric acid or $\left.\mathrm{SO}_{2}\right)$.

- Complexity $\left(10\right.$ to $\left.40^{5}\right)$ : indicates the difficulty of implementation due to process characteristics such as the number of steps, or the handling of both solids and liquids.

A range of 10 to 40 was retained for qualitative criteria in order to let the experts express their rankings of the different processes. Other criteria such as reliability or technical feasibility could have been retained, but were judged to be factored into other criteria. Safety issues are somewhat analogous to the environmental threat, and technical feasibility is related to the production cost and the maturity.

\subsubsection{Completion of the assessment matrix}

Once the processes and criteria were identified, the assessment matrix was sent for review. In this case, this step was performed at the same time with process and criteria definition and validation to fit a tight schedule. The experts were asked to provide a value for each criterion for each process in the assessment matrix. Generally, they only provided values for processes under development within their organisation. In case of disagreement on the values of the matrix, compromises were made to satisfy the group of stakeholders.

The most difficult criterion was production cost: assumptions were different depending on the countries, and also the level of detail applied. To meet the tight schedule, the experts were not asked to re-evaluate the assessments, but rather to detail how the calculations were performed. It was agreed that this assessment matrix is a first case study and that values from it should be considered carefully since they are not fully harmonised.

Table 2 presents the assessment matrix which was populated using data from many sources (Allen et al., 2009; Brown et al., 2003; Carles et al., 2009; Felder, 2007; Giaconia et al., 2007; 2008; Hauch et al., 2008; IEA/HIA Task 25, 2010a; 2010b; 2010c; 2010d; 2010e; INNOHYP CA, 2004; 2006; Jensen et al., 2007; Kolb et al., 2007; Kolb, 2009; Leybros et al., 2010a; 2010b), and of different kinds, classified here into three categories:

- data provided by experts (bold font in Table 2)

- data based on averages of the experts' data ${ }^{6}$

- $\quad$ qualitative expert's assessments (italics in Table 2). 
Table 2 Hydrogen production processes' assessment matrix

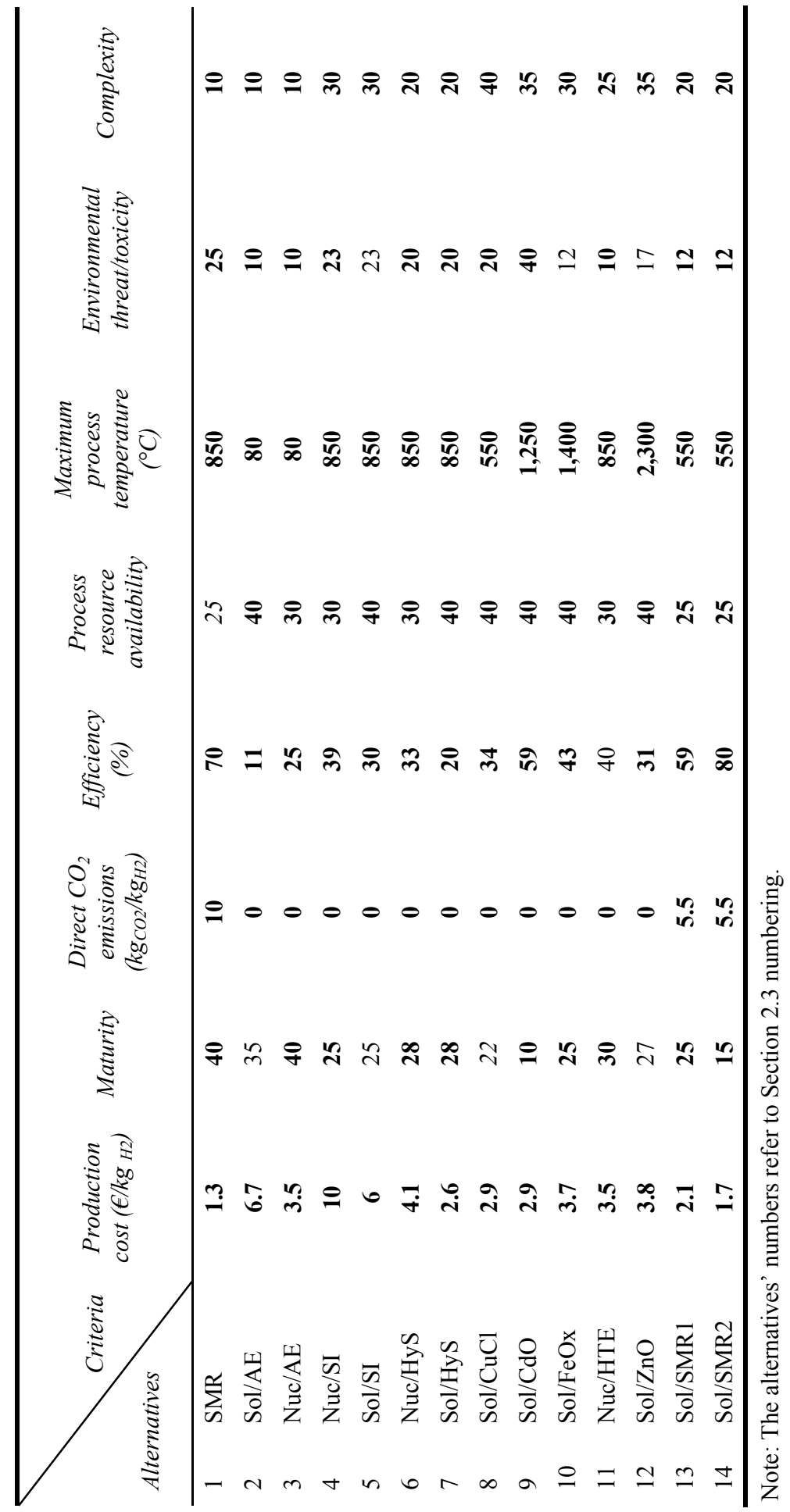




\subsubsection{Attribution of criterion weights}

Concerning the criterion weights, the group members were asked to rank the criteria. The transformation of ranks into weights was carried out as below (Maystre et al., 1994):

- first the criteria were classified from the least important to the most important taking into account the equalities (i.e., two criteria having the same rank) and the blanks (i.e., having a rank left blank, without any criterion)

- each criterion, including the blanks, was assigned a weight; the least important criterion was assigned 1 , the next one 2 , and so on

- if there were several criteria which had the same rank, their weight was the average of the criterion weights of this rank; otherwise the weight was defined by the previous step

- the relative weight (expressed as a percentage) was then obtained by dividing the criterion weight by the sum of the weights excluding the blanks

- the weights were rounded to verify that their sum is $100 \%$.

It was evident that the experts had different opinions concerning the importance assigned to each criterion. Two different visions could be distinguished among the rankings provided by the experts (each expert providing only one ranking). This led to the identification of two scenarios, as envisaged by B. Roy as a possibility in the 'European' conception of decision aiding in Roy (2010). In this case, the questioning protocol led to the retention of several sets of weights to define different scenarios. For a given scenario, each criterion weight was calculated from the average of the weights assigned by the experts (Maystre et al., 1994).

- Short-term scenario

The first scenario will be referred to as 'short-term' because economic and process feasibility criteria are prominent.

Table 3 summarises the criterion weights. This kind of scenario could correspond to the vision of an industrial stakeholder. In this scenario, the production cost is the most important criterion followed by three other criteria with the same importance, while the other criteria do not have a significant weight.

- Long-term scenario

The second scenario will be referred to as 'long-term' since environmental criteria are favoured. Table 3 also summarises the criterion weights of this scenario. In this scenario, while $\mathrm{CO}_{2}$ is the most important criterion, there is not much difference between the weights of the next criteria. This is perhaps a limitation of the methodology when there is not a single decision maker. The decision to deal with conflicting evaluations using averages of the weights assigned by the experts led, for the long-term scenario, to a common preference model which is not very discriminating.

These two scenarios acknowledge that two value systems were identified in the expert group. The fact that the efficiency has a low rank in both scenarios means that, according to the defined value systems, it does not appear as a key driver to implement a process 
(when compared to other criteria), although naturally it has a strong bearing on the production cost.

Table 3 Criterion weights

\begin{tabular}{lcc}
\hline Criteria & Short-term weights (\%) & Long-term weights (\%) \\
\hline Production cost & 24 & 14 \\
Direct $\mathrm{CO}_{2}$ emissions & 17 & 22 \\
Maturity & 17 & 10 \\
Complexity & 17 & 10 \\
Toxicity/environmental threat & 10 & 17 \\
Maximum process temperature & 5 & 5 \\
Efficiency & 5 & 3 \\
Process resource availability & 5 & 19 \\
\hline
\end{tabular}

\section{First results and discussion}

\subsection{Reference case}

\subsubsection{Reference case definition}

As explained in Section 2.2, the analysis is performed by setting threshold values. Results are first provided for what is called the 'reference case' in which no threshold is included (no preference, no indifference, and no veto). The impact of the methodology parameters will be then assessed by carrying out other case studies.

When setting the different thresholds, the dilemma was between not having the parameters too flexible because all of the processes would then be equivalent (e.g., setting an indifference threshold of ten for the $\mathrm{CO}_{2}$ emissions criterion would have made all processes equivalent for this criterion) and not having them too restrictive because the processes would be unable to be compared. This could happen if a very high concordance threshold was set, precluding global concordance indices higher than the concordance threshold, in which case no outranking relationship would be established. In both cases, the results would be useless. Thus, both scenarios have been studied with several concordance thresholds each. The maximum attainable value for the concordance index is $s_{\max }=1-\min _{j} k_{j}$ with $k_{j}$ being the weight of the criterion $j$. In fact, $C(a, b)=s_{\max }$ means that all the criteria accept the assumption 'the action $a$ outranks the action $b$ ' except the one having the weakest weight ${ }^{7}$.

For the 1st scenario, the 'weakest' criteria are the maximum process temperature, the efficiency, and process resource availability with 5\% weight; the efficiency has the lowest weight in the 2 nd scenario with $3 \%$.

For the present study, a maximum concordance threshold value of 0.94 was chosen. For each scenario, the analysis was performed for four concordance threshold values in order to examine the sensitivity of the kernel to this parameter (the selected values are: $0.94,0.84,0.74$ and 0.64 in order to cover the range 0.5 to $s_{\max }$ ). When this threshold increases, more processes can enter the kernel as non-comparable (it is 'harder' for a process to outrank another one since the concordance threshold is high). When it 
decreases, more equivalence is allowed (possible generation of artificial processes, i.e., several processes gathered in a new one because of their comparable performances for the considered criteria).

\subsubsection{Short-term scenario results}

Figure 3 displays the final outranking graph for a concordance threshold of 0.74 (selected because of its intermediate value of the concordance threshold). Each process is symbolised by a vertex. Outranking relationships are quite numerous (each outranking relationship being symbolised by an arrow pointing from the process which is outranking towards the process which is outranked).

For all concordance thresholds, nuclear alkaline electrolysis is within the kernel for the first scenario. This result is quite logical since alkaline electrolysis is the most mature process, has the lowest $\mathrm{CO}_{2}$ emissions, is the least toxic and the least complex, and has a production cost below the average production cost of the processes considered.

For the first three concordance thresholds, steam methane reforming is also found within the kernel. Despite having the highest $\mathrm{CO}_{2}$ emissions and this criterion being ranked the second most important, it still is within the kernel due to its low production cost. In these cases steam methane reforming is not comparable with the other processes (it cannot be declared either superior or inferior to the others) since it is the cheapest one and since there is not any veto for the $\mathrm{CO}_{2}$ criterion.

However, for the least restrictive case (i.e., lowest concordance threshold: $s=0.64$ ), steam methane reforming is no longer within the kernel. It is outranked by nuclear alkaline electrolysis whereas it was not comparable with it in other cases. $\mathrm{CO}_{2}$ emissions, process resource availability, maximum process temperature and toxicity criteria all favour the outranking of steam methane reforming by nuclear alkaline electrolysis. The low production cost is not enough, even in this short-term scenario, and other criteria rule steam methane reforming out.

When increasing the concordance threshold other processes enter the kernel. Among the most interesting are the appearance of the solar hybrid sulphur cycle and the solar copper chloride cycle. They belong to the kernel because they are not comparable with nuclear alkaline electrolysis, due to higher performance on the production cost and resource availability criteria.

\subsubsection{Long-term scenario results}

Unlike the short-term, there is no clear 'favourite' process. In this scenario, nuclear alkaline electrolysis can be outranked by other processes, as less importance is assigned to the production cost criterion.

This scenario gives higher significance to environmental criteria: assigning the greatest weighting to the direct $\mathrm{CO}_{2}$ emission criterion $(22 \%)$ has increased the values of the concordance indices. One should note that almost all the processes do not emit any $\mathrm{CO}_{2}$, so they are equivalent according to this criterion. Consequently, there are many outrankings (i.e., many arrows) as it can be seen in Figure 4 (long-term scenario results) when compared to Figure 3 (short-term scenario results).

When, at the same time, two or more actions outrank and are outranked by one another (due to close performances for instance), they form a 'circuit' and are substituted by an artificial equivalent action. In this case outrankings need to be added or removed in 
order to compare the new action to the initial ones. In the long-term scenario, artificial processes are created reflecting the equivalence of some processes (e.g., process 15 which represents three processes in Figure 5: solar and nuclear alkaline electrolysis and high temperature electrolysis), which belong to the kernel.

The fact of having similar criterion weights in the long-term scenario leads to this situation, because of the greater degree of difficulty in differentiating between processes.

As for the short-term scenario, new processes appear in the kernel when the concordance threshold is higher. Some of these processes that were not identified in the short-term scenario are now considered interesting for the long-term scenario, like nuclear high temperature electrolysis, the solar $\mathrm{Zn} / \mathrm{ZnO}$ thermochemical cycle and the solar ferrite cycle. This highlights the importance of the criterion ranking: depending on what matters the most, different processes could be selected.

\subsection{Sensitivity analysis}

\subsubsection{Case definition}

The previous study (reference case) was performed with the criteria considered as 'true' [i.e., the preference and indifference thresholds are set to zero $(q=p=0)$ ]; and no veto was included either. It is also important to understand how the results evolve when the methodology parameters are modified. The sensitivity analysis examines the variation of the results stemming from modification of the input data.

Such modifications:

- enable taking into account the uncertainty of the data and the hypotheses that were made (sensitivity to the assessment matrix values)

- verify the coherence of the method and its independence from the analyst subjectivity (i.e., sensitivity to the method parameters).

The input data, which may be varied, are the value of the assessment matrix and the criteria thresholds. The chosen thresholds are given in Table 4. Note that the criterion weights have not been modified since the analysis has already been performed for two different scenarios corresponding to two different sets of criterion weights.

Table 4 Threshold definition for the sensitivity analysis

\begin{tabular}{lccc}
\hline Parameters & $\begin{array}{c}\text { Indifference } \\
\text { threshold } q\end{array}$ & $\begin{array}{c}\text { Preference } \\
\text { threshold } p\end{array}$ & $\begin{array}{c}\text { Veto } \\
\text { threshold } v\end{array}$ \\
\hline $\begin{array}{l}\text { Production cost } \\
\text { Maturity }\end{array}$ & 0.5 & 2 & 3 \\
Direct $\mathrm{CO}_{2}$ emissions & 5 & 5 & No veto \\
Efficiency & 0 & 0 & No veto \\
Process resource availability & 10 & 10 & No veto \\
Maximum process temperature & 10 & 0 & No veto \\
Environmental threat/toxicity & 0 & 5 & No veto \\
Complexity & 5 & 5 & No veto \\
\hline
\end{tabular}


The adopted approach for the sensitivity analysis is progressively to:

- modify the method parameters (indifference, preference, veto and concordance thresholds)

- modify some of the assessment matrix values

- combine both modifications.

Thus, the sensitivity analysis will be based on different combinations of the single modifications that are defined below:

- doubling or quadrupling the steam methane reforming production cost which is the cheapest process [such production costs could be reached by 2030 or 2050 due to the increasing energy price (IEA, 2008)]

- halving or quartering the nuclear sulphur iodine production cost which is the most expensive process in the present assessment

- considering all the criteria as true (no preference or indifference threshold)

- considering an indifference threshold for the production cost criterion

- considering a preference threshold for the production cost criterion

- considering a veto threshold for the production cost criterion

- considering indifference thresholds for all criteria.

Thus, 15 cases were studied with several concordance thresholds for each case. It should be underlined that the choice of the thresholds is made in order to:

- not withdraw many processes from the beginning of the evaluation: no veto was then added except for the production cost criterion

- be coherent with the assessment values: no preference nor indifference was fixed for the $\mathrm{CO}_{2}$ and temperature criteria since there are widely different values (setting a threshold in these cases would either not change anything or make all the processes equivalent)

- allow the impact of indifference and preference thresholds to be seen by increasing comparability when the production cost is changed.

\subsubsection{Sensitivity study results}

The introduction of indifference and preference thresholds for the production cost increases comparability (indifference or weak preference) between the processes. The kernels are composed of the same processes or fewer if new outrankings are established. Consequently, nuclear alkaline electrolysis still stands out for the short-term scenario.

The introduction of a veto threshold for the production cost does not change the kernels. Actually, the same processes or more would be in the kernel if there is a veto for an outranking: some outrankings could disappear and make new processes enter the kernel. Steam methane reforming could belong to the kernel when it expresses its veto against solar alkaline electrolysis but it did not because it remains outranked by nuclear alkaline electrolysis. 
The introduction of indifference thresholds for all the criteria allows more indifference relationships between the processes: thus the values of the concordance indices in this case are higher than in the reference case. This implies more outrankings and fewer processes in the kernel (or artificial process creation). The effect is as if the concordance threshold was decreased. In fact, when an action $a$ is indifferent to an action $b$, then they outrank each other.

For instance, in the long-term scenario, for the lowest concordance threshold, all the processes are within the kernel as an artificial equivalent process.

Doubling the steam methane reforming production cost is not enough to change the results. Steam methane reforming only leaves the kernel in the short-term scenario when its production cost is multiplied by four. In this case, which is more heavily weighted towards economic criteria, it is outranked by nuclear alkaline electrolysis, which becomes cheaper.

In contrast, even dividing the nuclear sulphur iodine production cost by four does not affect the results: the kernels remain the same in the different cases. Nuclear sulphur iodine is in particular outranked by the solar sulphur iodine, due to higher process resource availability. Reducing the production cost is not enough to improve this process, since it does not have 'good' evaluations against the other criteria. This highlights the need for R\&D studies to increase the performance characteristics of this process.

Finally, another case study was carried out based on the long-term scenario, after having removed the $\mathrm{CO}_{2}$ emission criterion. Consequently, only the carbon-free processes were then considered in the study (all steam methane reforming processes were removed). This scenario appeared to provide stable results: only alkaline electrolysis appears in the kernel at different concordance thresholds. After having also removed this benchmark process, to focus on the longer term, five processes were found to stand out: nuclear high temperature electrolysis; and the solar hybrid sulphur, copper chloride, ferrite and $\mathrm{Zn} / \mathrm{ZnO}$ cycles. For a nuclear source, only one process is identified, whereas four processes are still considered for a solar heat source. From these results, it could be advised that in a medium term deployment perspective $R \& D$ should focus on these processes, while major progress needs to be demonstrated on the other ones and only longer-term deployment could be envisaged.

\section{Conclusions and outlook}

This study has conducted a first pass application of the MCDM method to hydrogen production processes. The methodology has been used to explore a set of processes identified by the group of experts from the IEA/HIA Task 25, and assessed according to a set of criteria accepted by the same group.

The purpose of this work is not to identify the 'best' process but to highlight, for each process, whether its weaknesses and strengths enable it to compete with other potentially promising processes. One major interest of the method is providing a framework for discussion and debate, especially since several stakeholders are involved.

Two different scenarios were considered, a short-term scenario and a long-term scenario. In the short-term scenario, nuclear alkaline electrolysis was the most favourable process. This is quite logical, as this process is the reference for $\mathrm{CO}_{2}$-free hydrogen production today. A sensitivity analysis on these results confirmed that the methodology produced a stable and consistent result. 
In long-term scenario, the study highlights that the results are very sensitive to the input assumptions, as could be expected. This is especially true for unrestrictive requirements (low concordance thresholds), and there was no single process that stood out in all the studied cases: in each case a different kernel emerged.

The stability of the short-term scenario results reflects that the criterion weight attribution corresponds to a steady, economically driven vision. Such a preference model could belong to an industrial stakeholder. On the other hand, for the long-term scenario there is not any real gap between the weights of the criteria, and many have almost equivalent weights. It should also be noted that the direct $\mathrm{CO}_{2}$ emission criterion has the highest weight, yet almost all the processes are carbon-free. This leads to much equivalence, and many outrankings must be added or removed in order to identify the kernel, which disturbs the stability of the results. It was seen in the final study that the stability could be achieved through a proper revision of the preference model.

Decision makers such as politicians willing to fund $R \& D$, or industrial companies needing to implement hydrogen production processes can apply this method to extract their own subset of processes from the alternatives, according to their system of values defined through the selection of criteria and the associated weights.

The methodology is a thinking process in which iteration is allowed and included: assumptions may be revised as well as preferences. This is why, after having demonstrated the consistency of the method, further studies are now planned to improve the assessment of high temperature processes in a $\mathrm{CO}_{2}$-free perspective.

The multicriteria assessment allows an evaluation of the potential promise of the processes in the medium and longer term. The results of this work can therefore be a valuable input into the R\&D strategy for high temperature hydrogen production processes. This is the focus of another sub-task of Task 25, to finally provide recommendations to the International Energy Agency on R\&D priorities.

\section{References}

Afgan, N.H., Veziroglu, A. and Carvalho, M.G. (2007) 'Multi-criteria evaluation of hydrogen system options', International Journal of Hydrogen Energy, Vol. 32, No. 15, pp.3183-3193.

Allen, D., Pickard, P., Patterson, M. and Sink, C. (2009) 'NHI economic analysis of candidate nuclear hydrogen processes', Paper presented at the 4th NEA Information Exchange Meeting on Nuclear Production of Hydrogen, 13-16 April, Oak Brook, Illinois, USA.

Andress, R.J., Huang, X., Bequette, B.W. and Martin, L.L. (2009) 'A systematic methodology for the evaluation of alternative thermochemical cycles for hydrogen production', International Journal of Hydrogen Energy, Vol. 34, No. 9, pp.4146-4154.

Brown, L.C., Besenbruch, G.E., Lentsch, R.D., Schultz, K.R., Funk, J.F, Pickard, P.S., Marshall, A.C. and Showalter, S.K. (2003) 'High efficiency generation of hydrogen fuels using nuclear power', General Atomic Project Report No. 30047.

Carles, P., Vitart, X. and Yvon, P. (2009) 'CEA's assessment of the sulfur-iodine cycle for hydrogen production', Paper presented at the 4th NEA Information Exchange Meeting on Nuclear Production of Hydrogen, 13-16 April, Oak Brook, Illinois, USA.

Ewan, B.C.R. and Allen, R.W.K. (2005) 'A figure of merit assessment of the routes to hydrogen', International Journal of Hydrogen Energy, Vol. 30, No. 8, pp.809-819.

Felder, R. (2007) 'Well-to-wheel analysis of renewable transport fuels, synthetic natural gas from wood gasification and hydrogen from concentrated solar energy', PhD thesis, ETH, Zürich, Switzerland, doi:10.3929/ethz-a-005540202. 
Figueira, J., Mousseau, V. and Roy, B. (2005) 'ELECTRE methods', in Springer Science, J. Figueira, S. Greco, and M. Ehrgott (Eds.): Multiple Criteria Decision Analysis: State of the Art Surveys, pp.133-162, Boston, Dordrecht, London.

Giaconia, A., de Falco, M., Caputo, G., Grena, R., Tarquini, P. and Marrelli, L. (2008) 'Solar steam reforming of natural gas for hydrogen production using molten salt heat carriers', AIChE Journal, Vol. 54, No. 7, pp.1932-1934.

Giaconia, A., Grena, R., Lanchi, M., Liberatore, R. and Tarquini, P. (2007) 'Hydrogen/methanol production by sulphur-iodine thermochemical cycle powered by combined solar/fossil energy', International Journal of Hydrogen Energy, Vol. 32, No.4, pp.469-481.

Graf, D., Monnerie, N., Roeb, M., Schmitz, M. and Sattler, C. (2008) 'Economic comparison of solar hydrogen generation by means of thermochemical cycles and electrolysis', International Journal of Hydrogen Energy, Vol. 33, No. 17, pp.4511-4519.

Hauch, A., Ebbesen, S.D., Jensen, S.H. and Mogensen, M. (2008) 'Highly efficient high temperature electrolysis', Journal of Materials Chemistry, Vol. 18, pp.2331-2340.

IEA (2008) World Energy Outlook, ISBN: 978-92-64-04560-6.

IEA/HIA Task 25 (2010a) IEA/HIA Task 25: High Temperature Hydrogen Production Process, High Temperature Electrolysis, available at http://www.ieahia.org/.

IEA/HIA Task 25 (2010b) IEA/HIA Task 25: High Temperature Hydrogen Production Process, Hybrid Sulphur Process, available at http://www.ieahia.org/.

IEA/HIA Task 25 (2010c) IEA/HIA Task 25: High Temperature Hydrogen Production Process, Steam Methane Reforming, available at http://www.ieahia.org/.

IEA/HIA Task 25 (2010d) IEA/HIA Task 25: High Temperature Hydrogen Production Process, Sulphur-Iodine Cycle, available at http://www.ieahia.org/.

IEA/HIA Task 25 (2010e) IEA/HIA Task 25: High Temperature Hydrogen Production Process, $\mathrm{Zn/ZnO}$ Thermochemical Cycle, available at http://www.ieahia.org/.

INNOHYP CA (2004) 'Innovative high temperature processes for hydrogen production', EC/FP6 Project SES6-CT-2004-513550, Data collection within the project (Reports D4, D5, D9).

INNOHYP CA (2006) 'Innovative high temperature processes for hydrogen production', EC/FP6 Project SES6-CT-2004-513550, Final Report, November 30.

Jensen, S.H., Larsen, P.H. and Mogensen, M. (2007) 'Hydrogen and synthetic fuel production from renewable energy sources', International Journal of Hydrogen Energy, Vol. 32, No. 15, pp.3253-3257.

Kolb, G.J. (2009) 'Status of USA's solar hydrogen generation research (SHGR) project', Presented at the IEA/HIA/Task 25 Cadarache Meeting, June 4, Cadarache, France.

Kolb, G.J., Diver, R.B. and Siegel, N. (2007) 'Central-station solar hydrogen power plant', Journal of Solar Energy Engineering, Vol. 129, No. 2, pp.179-183.

LAMSADE (2009) LAMSADE Presentation, available at http://www.lamsade.dauphine.fr/ (accessed on 4/1/2009).

Lewis, M.A. and Masin, J.G. (2009) 'Evaluation of alternative thermochemical cycles, Part II: the down-selection process', International Journal of Hydrogen Energy, Vol. 34, No. 9, pp.4125-4135.

Lewis, M.A., Masin, J.G. and O'Hare, P.A. (2009) 'Evaluation of alternative thermochemical cycles, Part I: the methodology', International Journal of Hydrogen Energy, Vol. 34, No. 9, pp.4115-4124.

Leybros, J., Gilardi, T., Saturnin, A., Mansilla, C. and Carles, P. (2010a) 'Plant sizing and evaluation of hydrogen production costs from advanced processes coupled to a nuclear heat source. Part I: sulphur-iodine cycle', International Journal of Hydrogen Energy, Vol. 35, No. 3, pp.1008-1018.

Leybros, J., Saturnin, A., Mansilla, C., Gilardi, T. and Carles, P. (2010b) 'Plant sizing and evaluation of hydrogen production costs from advanced processes coupled to a nuclear heat source. Part II: hybrid-sulphur cycle', International Journal of Hydrogen Energy, Vol. 35, No. 3, pp.1019-1028. 
Maystre, L., Pictet, J. and Simos, J. (1994) Méthodes multicritères ELECTRE: Description, conseils et cas d'application à la gestion environnementale, Presses polytechniques et universitaires romandes.

McDowall, W. and Eames, M. (2007) 'Towards a sustainable hydrogen economy: a multi-criteria sustainability appraisal of competing hydrogen futures', International Journal of Hydrogen Energy, Vol. 32, No. 18, pp.4611-4626.

McLaughlin, D.F., Paletta, S.A., Lahoda, E.J. and Kriel, W. (2006) 'Revised capital and operating HyS hydrogen production costs', Paper presented at the 2006 International Congress on Advances in Nuclear Power Plants, ICAPP'06, 4-8 June, Reno, NV, USA.

Roy, B. (1985) Méthodologie Multicritère d'Aide à la Décision, in English: Multicriteria Methodology for Decision Aiding, 1996, Economica, Paris.

Roy, B. (2010) 'Two conceptions of decision aiding', International Journal of Multicriteria Decision Making, in press.

Saaty, T.L. (1980) The Analytical Hierarchy Process: Planning Setting Priorities, Resource Allocation, McGraw-Hill, New York.

Yang, K.J., Lee, K.Y. and Lee, T.H. (2008) 'Preliminary cost estimates for massive hydrogen production using SI process', Paper presented at the 4th International Topical Meeting on High Temperature Reactor Technology, HTR2008, September 28-October 1, Washington, DC, USA.

Yüzügüllü, E. and Deason, J.P. (2007) 'Structuring objectives to facilitate convergence of divergent opinion in hydrogen production decisions', Energy Policy, Vol. 35, No. 1, pp.452-460.

\section{Notes}

1 A pseudo-criterion means that it is associated to an indifference and a preference threshold that are not equal to zero (these thresholds will be defined in next section). On the contrary, a criterion is 'true' when these thresholds are equal to zero. For such a criterion: the action $a$ is indifferent to the action $b$, only if their assessments are strictly equal. Otherwise either $a$ is preferred to $b$, either $b$ is preferred to $a$.

2 Maturity scale: 10: R\&D; 20: laboratory scale; 30: large experimentation; 40: industrial deployment.

3 Process resource availability scale: 10: limited in the short-term; 20: limited in the medium term; 30: limited in the long-term; 40: unlimited.

4 Environmental threat/toxicity scale: 10: lack of toxicity; 20: potentially toxic; 30: toxic; 40 : very toxic.

5 Complexity scale: 10 : simple; 20: little complex; 30: fairly complex; 40: very complex.

6 When evaluations were provided by several experts for the same process, the final value was assessed from average calculations.

7 If a process was worse than another one for each criterion, there would be no point in examining it because it could never appear in the promising processes, being always defeated by another process. 